\title{
MILITARY TERMINOLOGY - MEANINGS AND GRAMMAR APPROACH
}

\author{
Ileana-Gentilia METEA \\ "Nicolae Bălcescu" Land Forces Academy, Sibiu, Romania \\ meteaileana@yahoo.de
}

\begin{abstract}
The aim of this article is to analyze the basic phrases from the operational plans / orders by explaining concepts such as mission and execution, together with their elements, from a semantic and grammatical approach, and also by adding plastic elements in order to facilitate the understanding of the debated topics.
\end{abstract}

Keywords: military terminology, "execution", "mission"

\section{Introduction}

Standardization is a defining element of the military organization. The standardized language is part of a category of terminologies with newly extra-linguistic potential. Military operational language is part of the standardized language category, characteristic for certain areas of professional activities, science, technics and technology.

In military-specific activities we accept patterns that we do not master very well as meaning, but we accept them and implement them as we receive them. We have developed robotic abilities that allow us to translate certain ideas into a certain format, in conformity with the old axiom according to which the communication process can be represented by transmitting the message from the emitter to the receiver using a common language, encoding, a transmission channel, and decoding. This phenomenon might not be considered as eminently positive or negative, thus should be analyzed from the perspective of its usefulness in fulfilling military purposes (in the field).

\section{Analysis of the military terms}

In this analysis, we have started from very common words in the military environment that have a connotation related to the activities in the field: mission, execution, purpose, tasks, key tasks, end state etc.

The second part of an operation order mission, is a common noun with strong sonority and interesting etymology "[mission f. (Latin missio, -ónis, d. Mittere, missum, to send.). Task, power given to someone to do something in ones behalf: a diplomatic mission, for example the apostles of Jesus Christ had the mission of preaching the gospel. 1. Empowerment given to someone, task to do a certain thing. 2. A group of (officials) people sent in a foreign country for a specific purpose (usually diplomatic); delegation. Diplomatic Mission = Embassy or Diplomatic Office, headed by an ambassador or a plenipotentiary minister. 3. Action of Promotion of Christianity in countries with another dominant religion; (Collectively) priests sent into such an action; P. Ext. The name of the religious mission center (3). 4. Role, place, duty, purpose. [Pr: -si-u-. - Var: (vv., 1) missions. F.] - from fr. Mission, lat. Missio, -onis. "[1] 
Although the correspondence of terms is made by the verb of the third conjugation "to send" at infinitive, as first meaning given by the dictionaries, both the multivalent noun and the empowerment noun are used, showing that the mission includes both an action that usually involves movement and also an emotional load of a certain magnitude. Thus, the action is an important, value-bearing one, a locomotive that has the consequences of the mission are attached.

Metaphorically, the word "mission" can be compared with a snail with its harsh and mysterious shell, carrying a soft core in its womb that is moving in a movement intended only by him or a walnut with a spherical and hard bark, streaked with ribbons that send modulations encrypted to the its coarse and its hard core. Unlike snail, the walnut is attracted to gravity only, while the snail moves on the hard surface directed by an internal neuronal command. So the mission can include a multitude of methods, processes, tracking targets, precise and multidimensional goals. The mission is therefore a powerful common noun, that hides a polyvalent verb. This is the descriptive value of the mission passed through the filter of our subjectivism but keeping the terminological objectivism. Trying to replace the term with another from the same semantic sphere, we find: "embassy", "apostolate", "commission", "duty", "delegation", "deputy", "deputation", "evangelization", "empowerment", "assignment", "bound", "office", " purpose", "diplomatic mission", "role", "purpose", "priesthood", "task", "message", "vocation", and one may find out that most synonymous terms either express only partially the meaning transmitted by "mission", or the terms are totally apart from it, moving to the loss of the desired meaning.

In order to have a clear picture of the flexion modulations the noun receives in number and case one can observe the clarity of the flexion marks, the "mission" being a noun that submits to the flexion rules, that does not deviate from the rule, does not lack and does not lose any plural or case termination. Therefore, the noun "mission" from the "center" of the military action fits perfectly into the typical military terminology, and is suitable, both semantically and grammatically.

\section{Terminological explication}

In NATO's view, the mission is "a clear and concise sentence that refers to the task and its purpose set by the higher echelon" [2].

In the Romanian military thinking, the mission is defined as "the clear and concise expression of the action and the purpose to be accomplished" [3]. The purpose of the "action to be executed in combat by a military or a military structure" [4] is the combat mission. "This is established by the commander of the higher echelon and transmitted by order, in a clear and precise form, together with the main elements that contribute to its fulfillment (support, cooperation." [5] Based on the mission of the upper echelon, the commander states the mission "reflecting the current situation." [6]

In order to clarify the objectives pursued in the future, in this part are listed the additional tasks of the mission (e.g.: "destroy"," neutralize ", ...). The preferred form is "Who", (for example: the company, the battalion); "What", (for example: the main objective of the mission); "When", (for example: no later than ...); "Where", (for example: in the ... area); and "why" (the purpose of the mission). The mission statement may also include the type of operation (offensive or defense) and the control measures to be used (such as "targets" or "combat positions"). [7]

The question "who" (for example, the company, the battalion, ... who performs the mission, who implements the orders) indicates the structure that performs the mission. The question refers to the object that the subject's action is pointed towards, in accordance with the objective pursued by 
the mission, main and secondary ones (for example: the main objective of the mission). Finally, the relatives appear: "when" (for example: no later than ... ), "where" (for example, in the area of operations ...) and "why" (mission purpose). Time, space and relative clauses state the coordinates of the mission (when, where, how, why).

Terminologically, following the mission, the term "execution" refers to an action and can be represented by a compass: arms joined at a point of origin or origin, sharp peaks, and finally the perfect circle. I have intentionally omitted the rotation because it deserves special attention in its mechanical work which it performs according to the formulas indicated. In order to execute the missions stated in the operating orders, the mechanical work done by the compass arms often hides the effort of the execution structures. The impact of the sharp peaks on contact with the surface to be explored remains imperceptible. The defining importance of the execution is the product, the circle. It must be perfect, uninterrupted, undistorted. This is a standard execution.

Execution remains an aggressive verb with a noun form - a name for an action. Taken apart, the circle of "execution" is a collage of thoughts, calculations and movements, all linked together in schematic frames, in order to move inner and outer resorts, directed to the ultimate goal.

If we would try another terminological variant, we would find it hard to find a substitute in the semantic family of "execution": "performing", "fulfilling", "accomplishing", "application" are the translated terms from the dictionary of synonyms, none of which being the same as that used in the military field.

The intention contains a precise, concrete idea, without nuances, which has the path opened to materialization, being efficiently marked. This idea is materialized by the terminological name "purpose." The purpose is to transpose at the end of the action, the result (e.g., "to destroy / capture the enemy, precisely located in AO ZINC and to ensure the introduction of $100 \mathrm{In}$ Bde in combat" ). Military specialists tend to use the infinitive form of the verbs, because infinitive stands for name of actions (to introduce). The option can be explained by the fact that the infinitive mode is a verbal form that gives name to an action expressed in a general manner. The infinitive mode is used in the military language because: it does not change in time, number and person, has a limited flexion in composition to other modes; in the sentence has the syntactic role played by other categories of words, usually nouns; cannot play the role of predicate in the sentence; is not used together with the subject; is part of other tenses, along with auxiliary verbs. Thus, verbs at infinitive have only a denominational role and not a predicative one, they do not have a role of action. Infinitive verbs have the role of the noun, they act as nouns.

The "Key tasks" are reinforcements, intentional robot ligaments, rigid parts that must work perfectly, as an intelligent chain reaction, or as a perfect key for any lock. Key tasks contain nouns naming actions, names of verbs of movement (e.g. "conquering", "securing", "developing", "ensuring"). In the description of the key tasks we can encounter two distinct grammatical situations: noun verbs correlated with the preposition "for" and verbs in indicative mode, whose action is reflected by the indirect complement: participates at securing $\rightarrow$ the alignment; Participates at $\rightarrow$ offensive development.

The desired end state bears the mark of the participle - "destroyed/captured", using verbs cannot be misinterpreted and the reflexive diathesis of verbs that are understood from the context (e.g.: "100 In Bde in offensive in the ... direction").

The concept of operation projects us into the reflexive future (e.g. "The offensive operation will develop in ten phases." If we had to deal with a text other than the military, the expression would probably 
have been "as follows". We note that the military terminology is not permissive in sense but concise, with clear indications. In the description of the phases of the operations, the beginning and the final moment is indicated: "...begins with and finishes after ..." The concreteness of some lexically minimalized expressions explains a wide-ranging operational situations.

In order to determine the tasks of the maneuver structures, the movement-action is expressed by nouns creating visual and auditory images. The verbs on indicative reveals the active diathesis even in reflexive forms: "moves", "ensures", "takes", "destroys", "captures", "rejects" ..., returning to the initial form by "regrouping". Regarding the military style of communication, it is "distinguished by the use of the active diathesis" [8]. This is due to the fact that the active diathesis is direct, clear, easy to understand. By contrast, the passive diathesis can be vague, elusive, difficult to understand. In terms of communication, the active diathesis is more often used in the conversation than the other (we normally communicate in active diathesis). Moreover, in line with the specificity of the military style, the sentences in active diathesis are shorter than the sentences in the passive diathesis.

Analyzing the opportunity to use certain verbs, in the context of the military terminology, we find that linguistic expressions with maximum impact are used to describe effects on the enemy. "Destroy" and "neutralize" are two of the preferred verbal forms that have the contribution of vibrant consonants "d", "r", "g", "z", which together with the rest of the "deaf" consonants and linked by opened and closed vocal groups and create a linguistic conglomerate with a strong force of expression. It is unimaginable how it would have been if instead of the expression "destroy the enemy" one would use the verbs such as: "abolish", "devastates," or worse: "scatters", "crushes", "massacre" ... the enemy.

\section{Conclusion}

Concluding, military terminology, austere in its linguistic expression, referred to as a "wooden language" by the ignorant, contains in its elements a special symbolism, proving that the military system is not only a subsystem of the global social system but a distinct element of it. Military terminology is the linguistic expression of the military uniform. A coded language appears, that uses simple words in certain forms but resulting in precise effects. In the absence of such a encoded language, which can be decrypted by the performer, the understanding of the details of missions would be impossible, and practically "execution" on the field would be catastrophic. In this respect, we consider that the standardization format of the operation order is imperative, in order not to give way to interpretations. We draw attention to the fact that because military activities involve a tensioned situation, the military must be concerned with the execution of the mission and not necessarily with the in-depth understanding of the used terms. This also stands for those who issue operation orders, in the sense that these orders must be short, clear, and should ensure consistency of actions without leaving room for interpretation.

\section{References}

[1] https://dexonline.ro;

[2] Collective of authors, AAP-06, NATO Glossary of Terms and Definitions (English and French), 2016, p. 89.

[3] Collective of authors, Collection of Terms, Concepts and notions of Reference in the Fields of Military Policy, National Security and Armed Defense, Military Publishing House, Bucharest, 2008, p. 185. 
[4] Collective Author, Military Lexicon, Saka Publishing House, Chisinau, 1994, p. 224.

[5] Ibid. 4, p. 224.

[6] Ibidem 3, p. 185.

[7] Collective of Authors, F.T./I-1, Mechanized Brigade Manual (Infantry, Light Infantry), Bucharest, 2008, pp. 357-358.

[8] http://doctorat.ubbcluj.ro/sustinerea_publica/rezumate/2011/filologie/dochinoiu_

[9] fuiorea_elena_en.pdf, p. 18. 